\title{
PerCursos
}

\section{Submissão da agricultura à indústria, colapso ambiental e multifuncionalidade da agricultura no contexto brasileiro}

\section{Resumo}

A industrialização da agricultura brasileira, iniciada na década de 1970, teve como externalidades negativas o esvaziamento populacional, degradação do solo, aumento das emissões de carbono, migração em massa para os centros urbanos, marginalização social. A partir da década de 1990, no contexto internacional das discussões sobre desenvolvimento sustentável, surge o conceito de multifuncionalidade da agricultura (MFA). Pautado na defesa de que a agricultura tem funções tais como a fixação das pessoas nos territórios, preservação e manutenção dos serviços ecossistêmicos e ordenação do equilíbrio social, acreditamos que este conceito favorece a discussão em prol de novos paradigmas produtivos mais sustentáveis.

Palavras-chave: Economia agrícola - Produção - Brasil. Desenvolvimento sustentável.
Gabriela Maria Leme Trivellato Mestranda em Ciências PPG Interunidades em Ecologia Aplicada ESALQ/CENA na

Universidade de São Paulo - USP. Brasil

gabriela.trivellato@usp.br

\section{Luciana Maria de Lima Leme}

Doutoranda em Ciências PPG Interunidades em Ecologia Aplicada ESALQ/CENA na Universidade de São Paulo - USP. Brasil luma-leme@hotmail.com

\section{Ademir de Lucas}

Doutor em Epidemiologia

Experimental Aplicada às Zoonoses pela Universidade de

São Paulo - USP. Técnico Especializado de Nível Superior Especialista em Extensão Rural e Organização de Produtores da Universidade de São Paulo - USP. Brasil addlucas@usp.br

\section{Para citar este artigo:}

TRIVELLATO, Gabriela Maria Leme; LEME, Luciana Maria de Lima; LUCAS, Ademir de. Submissão da agricultura à indústria, colapso ambiental e multifuncionalidade da agricultura no contexto brasileiro. PerCursos, Florianópolis, v. 21, n.47, p. 227 - 249, set./dez. 2020. 


\title{
Agriculture submitted to industry, environmental collapse and multifunctionality of agriculture in brazilian context
}

\begin{abstract}
The industrialization of Brazilian agriculture, which started in the 1970s, had as negative externalities population emptying, soil degradation, increased carbon emissions, mass migration to urban centers, social marginalization. From the 1990s, in the international context of discussions on sustainable development, the concept of multifunctionality of agriculture (MFA) emerges. Based on the defense that agriculture has functions such as settling people in territories, preserving and maintaining ecosystem services and ordering social balance, we believe that this concept favors the discussion in favor of new, more sustainable productive paradigms.
\end{abstract}

Keywords: Agricultural economy - Production - Brazil. Sustainable development. 


\section{Introdução}

Para Müller (1982, p. 49), o avanço da agricultura industrializada materializa interesses sociais modernos, levando à "expansão da burguesia e pequena burguesia industrializadas no meio rural." Por outro lado, a burguesia (e pequena burguesia) tradicionais diminuem. Há redução dos trabalhadores ditos autônomos, sendo eles pequenos arrendatários e parceiros. Por sua vez, crescem os assalariados, principalmente os sem-terra; aumentam os proprietários cuja produção destina-se a servir à indústria e ao comércio e, portanto, trabalham conforme seus ditames. Ocorrem modificações: 1. na composição de capital; 2. na difusão de tecnologia industrial e 3. nos mercados regionais, antes protegidos pelos custos logísticos e "dificuldades de remessa de produtos perecíveis", convertem-se em mercado nacional (MÜLLER, 1982, p. 50).

No mundo do pós-guerra, a solução para os problemas humanos estava no crescimento econômico e a chave para o crescimento dos países de Terceiro Mundo estaria no consumismo. Acreditava-se que superação de problemas sociais nos países de Terceiro Mundo, como a fome, não ocorria porque esses países não conseguiam se desenvolver. A ideia de desenvolvimento limitava-se ao desenvolvimento econômico, restringindo, portanto, a ideia de felicidade à satisfação de consumo. Essa noção de crescimento começou a apresentar, então, resultados irreversíveis do seu preço: danos à biosfera terrestre resultantes dos efeitos destrutivos e cumulativos da industrialização (CASTORIADIS, 1987).

As consequências virtuais ou efetivas de um 'crescimento' e de uma industrialização desenfreados começavam a delinear-se, imensas. A recente 'crise da energia' e a escassez de matérias-primas surgiram no momento apropriado para lembrar aos homens que não era nem mesmo certo que eles poderiam continuar por muito tempo a destruir a Terra. [...] Já que o sistema tinha sido criticado por preocupar-se unicamente com a quantidade de bens e serviços produzidos, novos organismos burocráticos foram estabelecidos para cuidar da 'qualidade de vida'. Como parecia haver aí um problema ambiental, ministérios, comissões e conferências internacionais foram organizados para resolvê-lo. (CASTORIADIS, 1987, p. 137) 
Para reagir à "crise ambiental", os "indicadores econômicos foram completados pelos 'indicadores sociais' ou 'indicadores de bem-estar', e novas linhas e colunas foram acrescidas às matrizes das transações industriais" (CASTORIADIS, 1987, p. 138). Ou seja, discutia-se a questão ambiental apenas em termos dos "custos" e "rendimentos", e do possível impacto das medidas de controle da poluição sobre as taxas de crescimento do PNB (Produto Nacional Bruto). Controlar medidas de "crescimento" em prol da questão ambiental podia trazer riscos ao acúmulo de capital, e, nesse sentido, investiu-se na nova "indústria de controle da poluição". Logo os maiores poluidores, as gigantescas companhias industriais, apropriaram em sua publicidade a frase "trabalho pioneiro em matéria de controle da poluição" (op. cit., p. 138). Portanto, apesar de posta a realidade dos problemas ambientais, a maior preocupação dos tomadores de decisão governantes e industriais influentes dos países "desenvolvidos" - era "saber se e como se poderia e se deveria 'internalizar' os custos do controle da poluição" (CASTORIADIS, 1987, p. 138).

A ideia de que o problema, em seu conjunto, ultrapassava de longe a questão dos 'custos' e dos 'rendimentos', na prática jamais chegou à mente dos economistas e políticos. Mesmo as reações mais 'radicais' [...] [das] camadas dominantes não questionavam, de fato, as premissas mais profundas das perspectivas oficiais. (CASTORIADIS, 1987, p. 138)

Visto que o crescimento criava problemas incontroláveis e que qualquer processo de crescimento exponencial devia inevitavelmente chocar-se, mais cedo ou mais tarde, com limites físicos, os mesmos tomadores de decisão optaram pela resposta "não ao crescimento" ou "crescimento zero" (CASTORIADIS, 1987, p. 138). Porém, não consideraram que, nos países "desenvolvidos", o crescimento era tudo o que o sistema tinha a oferecer e, logo, interrompê-lo era inconcebível, podendo levar a uma violenta explosão social, 
sociais existentes, será que os países 'desenvolvidos' aceitariam tornar a ser uma minoria impotente frente a países asiáticos, africanos e latinoamericanos tão ricos quanto eles e bem mais populosos? (CASTORIADIS, 1987, p. 139-140)

\section{Reprimarização da economia na américa latina e emergência da MFA na}

\section{europa}

"Projeto nacional-desenvolvimentista" foi o termo utilizado para caracterizar "o padrão de desenvolvimento adotado pelas sociedades latino-americanas, no período compreendido entre meados da década de 1940 e o início dos anos 1980" (LEITE, 2005, p. 280). Durante esse período, poucos desses países (México e Brasil) mantiveram o projeto de desenvolvimento nacional, uma vez que as "estruturas intervencionistas do capitalismo europeu e norte-americano" foram abaladas pela crise internacional, durante a década de 1970 (LEITE, 2005, p. 280). O Brasil manteve-se nesse projeto "até meados dos anos 1980, ainda que mergulhado numa profunda crise" (LEITE, 2005, p. 281).

[O] livro Sete ensaios sobre a economia brasileira [...] representou uma criativa proposta analítica, introduzindo uma visão que, na ocasião, já prenunciava o futuro polemista. Esse autor [Antonio de Barros Castro] foi notável interpretador dos processos econômicos do País brasileiro. [...] Castro [...] insistiu que na história nacional a agricultura não se constituíra em freio à industrialização, ainda que seu desenvolvimento não tivesse seguido uma via similar à dos países do capitalismo avançado. E advertiu [...]: sem a democratização da propriedade da terra, as regiões rurais exportavam a desigualdade social do campo para a cidade, por meio de processos migratórios das famílias mais pobres (BUAINAIN et al., 2013, p. 106).

O modelo de desenvolvimento econômico na América Latina - chamado de reprimarização da economia ou neoextrativismo (GUDYNAS, 2012; PETRAS, 2012) fundou-se na exportação dos recursos naturais e na produção agropecuária para exportação. Foi implantado devido à crise e à dívida externa desses países, que, em 1982, 
foram obrigados a aceitar as imposições internacionais e os parâmetros do Conselho de Washington. Como consequência, os países latino-americanos postergaram a soberania que pretendiam alcançar antes de implantarem esse modelo econômico de substituição de importações.

No Brasil, este modelo tornou mais efetiva a ação do Estado e melhorou o desempenho da macroeconomia. No entanto, o Estado era autoritário e havia desigualdade social (FIORI, 1992; LEITE, 2005; MARTINS, 1991). Nos anos 1980, o Brasil apresentava-se pouco adequado à estrutura desenvolvimentista, o que, para Portella Filho (1994), era consequência do modelo de substituição de importações (LEITE, 2005; PORTELLA FILHO, 1994). Logo, o "Projeto nacional-desenvolvimentista" brasileiro não foi capaz de produzir "alternativas compatíveis com as transformações internacionais operadas a partir da década de 1970" (LEITE, 2005, p. 281):

As transformações da agricultura brasileira [permaneceram] subordinadas às estratégias industrializantes, corroborando uma rápida modificação do quadro demográfico nacional que em 50 anos inverteu as participações das populações rural e urbana no país (de $70 \%$ de habitantes residentes no meio rural em 1930 para pouco menos que um terço da população total em 1980). O desenvolvimento do capitalismo no campo brasileiro iria manter, contudo, as características históricas da nossa formação social, incluindo a elevada concentração fundiária, além de assistir às assimetrias que pautaram a trajetória da industrialização nacional. (LEITE, 2005, p. 281)

Entende-se, pela teoria da dependência, que o subdesenvolvimento é gerido pelo desenvolvimento dos países desenvolvidos (FRANK, 1967). Existiam, portanto, limitações estruturais do atraso para que o modelo de substituição de importações funcionasse no Brasil e na Argentina. Isso porque não havia ocorrido uma transformação política e social que mudasse o cenário econômico e político a ponto de permitir um desenvolvimento autônomo dos países da América Latina (VÁSQUEZ CARDONA, 2014).

A literatura que analisa as diversas formas de reivindicação, luta e organização, bem como as novas propostas produtivas dos agricultores e 
sem-terra, tem realçado os esforços dos agricultores para viabilizar sua permanência no rural e na agricultura. No Brasil, a atividade agrícola em geral é menos regulamentada pelo Estado do que na Europa e na América do Norte, e as ações governamentais de apoio à agricultura familiar também são mais restritas. No entanto, o espaço para iniciativas e o espectro de possibilidades são mais abertos, ao contrário dos países de capitalismo avançado, nos quais os sindicatos, as organizações municipais e o Estado (além dos organismos ligados aos mercados comuns regionais) regulamentam mais os usos do espaço e a produção. (FERREIRA, 2002, p. 40)

Na Argentina, as políticas neoliberais foram implantadas desda a ditadura military de Videla, em 1976, perdurando até 2001. Estas políticas culminaram na contração da economina Argentina. Entre 1998 e 2002, a Argentina viveu o período de recessão mais forte de sua história. No Brasil, tais políticas foram implantadas a partir de 1982. Em 1986, a inflação no país cresceu $200 \%$, chegando a $1000 \%$ em 1989. Como resposta a isso, os governos no Brasil e na Argentina teriam fortalecido o papel regulador do Estado na economia, impulsionando setores industriais, melhorando a capacidade de consumo e estimulando o crescimento econômico, fundamental no setor produtivo. Isso parecia contradizer a as dificuldades econômicas desses países na década de 1980. No entanto, este modelo de desenvolvimento industrial se suportou em empresas multinacionais e poderes oligárquicos, que aproveitaram os benefícios econômicos dos créditos e garantias tributárias oferecidos pelos governos brasileiro e argentino. Além disso, o estímulo à produção de matérias-primas teve um grande peso na política econômica. Isso foi intensificado com a crise mundial de 2008, havendo elevação do preço dessas matérias-primas nos mercados internacionais (VÁSQUEZ CARDONA, 2014).

La expansión de cultivos para exportación es impulsada en la Argentina desde el gobierno nacional, que pretende con el PEA (Plan Estratégico Agroalimentario y Agroindustrial Participativo y Federal 2010-2020), aumentar el volumen exportable a 150 millones de toneladas (principalmente carnes, cereales y oleaginosas), sin discutir cómo se distribuiría la ganancia del incremento productivo, que se calcula pasaría de 39,358 a 99.710 millones de dólares, en un esquema concentrado donde el $60 \%$ de la producción se da en explotaciones de más de 1,000 ha7 (que son el $10 \%$ de los productores del país) y donde la 
comercialización y procesamiento esta manejada en un 90\% por siete grandes empresas trasnacionales (INTA, 2009).

En Brasil los cultivos de exportación, así como los cultivos para la producción de biocombustibles, se han visto estimulados desde las políticas del gobierno de Lula, haciendo productiva gran parte de la tierra de los antiguos facenderos. En el 2010 el agronegocio accedía al $85 \%$ del crédito, controlaba el $76 \%$ del área agrocultivable, producía el $62 \%$ de la producción agrícola del país, y contrataba tan solo al $26 \%$ de la población rural (Fernandes, Welchy Gonçalves, 2012). El agronegocio que promueven las empresas trasnacionales, para la producción de commodities, no solo avanza sobre las áreas más fértiles y con mejores condiciones de producción, sino que viene migrando a diversas regiones del Brasil, sustituyendo los cultivos tradicionales. Así la producción de caña de azúcar, eucalipto, soja y pino, obliga al movimento de las otras producciones agropecuarias; ejemplo de ello es la producción pecuaria migrando para la región de la Amazonía y agravando la tala del bosque tropical más importante del planeta (Fernandes, Welch y Gonçalves, 2012). (VÁSQUEZ CARDONA, 2014, p. 144).

Nesse contexto, no Brasil, agriculturas alternativas passam a emergir, como resultado do questionamento do modelo produtivista - ainda que em menor escala em comparação com os países europeus.

O movimento da agricultura alternativa apresenta uma grande vitalidade e repousa no crescimento do número de consumidores preocupados com a qualidade dos alimentos. No entanto, o perfil de renda da população urbana constitui ainda um freio para a generalização dessa expectativa de consumo: as preocupações ante a qualidade não ultrapassam a questão central do próprio acesso à alimentação. (FERREIRA, 2002, p. 38-39)

Os desenvolvimentistas da década de 1970, como Kurz (1999) e Mandel (1968), acreditavam que os países de terceiro mundo, como o Brasil, poderiam chegar a desenvolvidos. Hoje, a crença nessa ideia enfraqueceu-se, pois, sempre que um país é mais fraco na dinâmica mundial, há pressão para aceitar relações de troca desvantajosas. Acredita-se, portanto, em outras formas de desenvolvimento. Para Kurz (1999), enquanto predominar a lógica da mercadoria, predomina a lógica da desumanização das relações. 


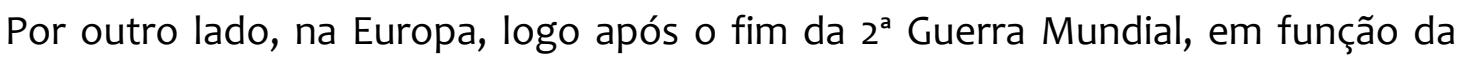
precariedade estrutural do setor produtivo agrário, designa-se à agricultura a função de garantir a reconstrução econômica e social dos países envolvidos no conflito (FRANCO ALVES; MALAGODI, 2014). Em 1947, fixa-se um mínimo de reservas alimentares de determinados produtos, para garantir preços e mercado para o restante da produção agrícola (FRANCO ALVES; MALAGODI, 2014).

Em 1957, através do Tratado de Roma, porém, inicia-se a discussão do papel da agricultura para a garantia da segurança alimentar, culminando, em 1962, com a proposta de uma Europa Verde, dando origem à Política Agrícola Comum (PAC). Essa PAC baseavase na modernização da agricultura, tendo como linha de conduta a produção de bens agrícolas voltados a atender ao ainda problemático abastecimento de alimentos, que fora totalmente desarticulado na década anterior. Portanto, tratava-se de uma política assentada na segurança alimentar (FRANCO ALVES; MALAGODI, 2014, p. 120).

Em 1958, passa a ser discutida a função da agricultura na ordenação do território e no equilíbrio social. Isso ocorre em função de sinais de precariedade socioeconômica e ambiental de alguns espaços agrários europeus. Esse contexto, somado à perspectiva de criação de um mercado comum, inspira a criação, na França, das Leis de Orientação Agrícola (LOA) de 1960 e 1962 (FRANCO ALVES; MALAGODI, 2014). Na França, a LOA torna-se a base legal e política do contrato entre o Estado e os agricultores e, através dela, além da função de produção, aparecem sinais assegurando à agricultura os objetivos de ocupação, segurança territorial e ordenação do espaço. Por meio dela, também são criados fundos de ação social para assegurar a presença de agricultores que tivessem suas terras em zonas desfavorecidas, com o objetivo de "efetuar o equilíbrio social e humano de certas zonas, que mereciam ser preservadas" (FRANCO ALVES; MALAGODI, 2014, p. 120). Essa proposta reconhecia que a presença dos agricultores nesses locais era indispensável e outorgava-lhes ajudas adaptadas às condições excepcionais dessas explorações nesses locais.

Mais tarde, é reconhecido o papel da agricultura como fixadora das pessoas no campo, no sentido de que o histórico das políticas agrícolas, em quase toda a Europa, durante as décadas de 1970 e 1980, viria a oficializar a ocupação territorial. "Em 1973, a 
função de ocupação do território encomendada à agricultura motiva a criação de empréstimos de instalação, para jovens agricultores" (FRANCO ALVES; MALAGODI, 2014, p. 120). A própria LOA de 1980 reconhece que os agricultores desempenham um importante papel na manutenção do patrimônio e dos equilíbrios rurais, e na preservação da agrobiodiversidade.

\section{Industrialização do campo brasileiro e multifuncionalidade da agricultura} (MFA)

$\mathrm{Na}$ industrialização do campo brasileiro, "a agricultura industrializada imprime a direção do devir de toda a agricultura nacional" (MÜLLER, 1982, p. 47). A agricultura torna-se bem de produção, por um lado, e bem de subsistência, por outro. Desfaz-se a ideia de propriedade territorial, surgem as rendas negativas, dá-se o empobrecimento da maioria dos pequenos proprietários, arrendatários e parceiros. São consequências "que tendem a regularizar as condições de produção e de vida no meio rural" (MÜLLER, 1982, p. 56). Transfere-se o modo de produção industrial para a agricultura, em termos da: aplicação do progresso técnico vigente; elevação das concentrações de capital; do "avanço de formas oligopólicas de estruturação de mercados, acentuando a distinção entre grandes e pequenos capitais" (MÜLLER, 1982, p. 50-51).

Para José de Arimatéia Rodrigues (1978), a política agrícola governamental no Brasil dedicou-se a "explorar a agricultura para financiar o crescimento industrial" em vez de "fomentar a produção agrícola e o bem-estar rural" (RODRIGUES, 1978, p. 36).

Como contraponto disso, no livro "Sete ensaios sobre a economia brasileira" (CASTRO, 1969) Antônio Barros de Castro alerta sobre "a perversidade do modelo brasileiro", procurando "demonstrar que o sistema econômico no Brasil tem sido capaz de expandir-se indefinidamente sem reformas sociais", o que significa que "os problemas sociais não estão sendo convertidos em problemas econômicos pela evolução da história” (BIELSCHOWSKY, 2011, p. 366-367). Ou seja, “a pobreza de parte da agricultura” no Brasil não impediu a expansão agrícola, e a "má distribuição de renda" não impediu a 
“acumulação capitalista e a expansão econômica". Isso implica reconhecer que "o modelo funciona, só que é perverso" (BIELSCHOWSKY, 2011, p. 366-367).

Para Mellor (1967), a agricultura possui três papeis principais: 1. Fornecimento de alimentos e fibras para uma população em expansão e com crescente poder aquisitivo; 2. Fornecimento de capital para a transformação econômica do país; 3. Aumento direto do bem-estar rural. Liberação de mão de obra e criação de mercado para o setor industrial seriam papéis complementares (MELLOR, 1967; RODRIGUES, 1978).

No contexto brasileiro, a mais difundida concepção de MFA é a dada por Maria José Carneiro e Renato Maluf (2003). Para eles, dentre as múltiplas funções atribuídas à agricultura, enfatizam-se quatro expressões na realidade rural brasileira: a) reprodução socioeconômica das famílias rurais; b) promoção da segurança alimentar das próprias famílias rurais e da sociedade; c) manutenção do tecido social e cultural; d) preservação dos recursos naturais e da paisagem rural (CARNEIRO; MALUF, 2003)'.

Quanto à "reprodução socioeconômica das famílias rurais", Carneiro e Maluf (2003) entendem que deve existir no meio rural geração de trabalho e renda que permitam às familias rurais manterem-se no campo em condições dignas. Relativamente à "promoção da segurança alimentar das próprias famílias rurais e da sociedade", referem-se à garantia da segurança alimentar em termos de disponibilidade, acesso e qualidade dos alimentos (CARNEIRO; MALUF, 2003).

O papel de "manutenção do tecido social e cultural" é executado por uma agricultura nos moldes da MFA, na visão de Carneiro e Maluf (2003), no sentido de que, na medida em que os agricultores têm condições de manterem-se dignamente

\footnotetext{
1 Para minimizar interpretações equivocadas da MFA, esta deve ser diferenciada dos conceitos de pluriatividades e atividades para-agrícolas. Sobretudo no que se refere à confusão de MFA com pluriatividades, comumente cometida em determinadas publicações. Seguimos a definição de Moruzzi Marques e Lacerda (2008, p.154), segundo os quais o conceito de pluriatividades limita-se à "atividade agrícola em tempo parcial associada, sobretudo, ao assalariamento em circunstâncias nas quais existam dinâmicos mercados de trabalho industrial ou de serviços". As atividades para-agrícolas estão inseridas na cadeia produtiva. Atividades em agroindústria, turismo rural ou preservação ambiental são para-agrícolas, desde que estejam associadas à unidade familiar de produção (MARQUES; LACERDA, 2008). Roux e Fournel (2003), consideram que os casos de agricultores que exercem diferentes atividades em tempo integral nas suas unidades se inscrevem sem problema algum no âmbito da MFA, não podendo ser confundidos com pluriatividades.
} 
trabalhando no contexto de agricultura, delineiam-se relações sociais. A manutenção dessas relações sociais permite o fortalecimento político e econômico da comunidade de agricultores, conforme demonstrado em diversos estudos, a citar Brandenburg (2008), Ferreira e Zanoni (2008), Bergamasco e Bueno (2008), Abramovay (1981) e Moruzzi Marques, De Lucas e Trivellato (2017)2.

A "preservação dos recursos naturais e da paisagem rural" considera as contribuições (ou danos) da agricultura à paisagem rural e ao patrimônio natural. Nessa lógica, o uso dos recursos naturais e a preservação da paisagem rural são fatores que proporcionam a reprodução das famílias rurais (CARNEIRO; MALUF, 2003).

\section{Capitalismo e subdesenvolvimento no Brasil}

Para Le Goff (1984), no século XX, a ideia de modernidade manifesta-se principalmente no campo da ideologia econômica, no sentido de que a construção da modernização dá-se pela ideia de desenvolvimento e aculturação, limitados à imitação da civilização europeia. Nesse contexto, a agricultura esmera-se pela produção crescente de alimentos a partir da utilização intensiva de agrotóxicos, na medida em que o aumento da produção visa ao lucro e não à segurança alimentar.

\footnotetext{
2 BRANDENBURG, Alfio. Colonos: subserviência e autonomia. In: FERREIRA, Angela Duarte Damasceno; BRANDENBURG, Alfio. (orgs.). Para pensar outra agricultura. 2. ed. Curitiba: Editora UFPR, 2008. p. 81-118. FERREIRA, Angela Duarte Damasceno; ZANONI, Magda. Outra agricultura e a reconstrução da ruralidade. In: FERREIRA, Angela Duarte Damasceno; BRANDENBURG, Alfio. (orgs.). Para pensar outra agricultura. 2. ed. Curitiba: Editora UFPR, 2008. p. 15-29.

BergamASCO, Sonia Maria Pessoa Pereira; BUENO, Osmar de Carvalho. Agricultura familiar e poder local: um exercício de cidadania. In: FERREIRA, Angela Duarte Damasceno; BRANDENBURG, Alfio. (orgs.). Para pensar outra agricultura. 2. ed. Curitiba: Editora UFPR, 2008. p. 119 -149.

ABRAMOVAY, Ricardo. Transformações na vida camponesa: o Sudoeste Paranaense. 1981. Dissertação (Mestrado em Ciências Sociais) - Universidade de São Paulo, São Paulo, 1981.

MORUZZI MARQUES, Paulo Eduardo; DE LUCAS, Ademir; TRIVELLATO, Gabriela Maria Leme. O Papel da Extensão Universitária no apoio à Agricultura Familiar no município de São Pedro/SP. In: Rev. Cult. Ext. USP, São Paulo, v. 18, p. 13-23, nov,. 2017.
} 
Para Dumont (1966; 1971; 1975; 1977), o maior problema do capitalismo é centrarse numa sociedade individualista. A contraposição do capitalismo, segundo Norbert Elias (1994) seria a interdependência entre os seres humanos. Ao encontro do que defendem esses autores, a MFA reconhece a importância das relações sociais entre os produtores rurais, no âmbito do cooperativismo (MORUZZI MARQUES; DE LUCAS; TRIVELLATO, 2017) e da economia solidária (TORUNSKY, 2019; MARQUES; DE GASPARI; ALMEIDA, 2017), tanto para sua reprodução socioeconômica, quanto para a preservação ambiental (TRIVELLATO; DOS SANTOS, 2019).

O rural brasileiro é perpassado pelas diversas estratégias dos seus principais atores - os agricultores - para permanecerem neste espaço social. Trata-se também de um rural dinamizado por movimentos sociais que propugnam a volta à terra, tanto para os agricultores que não a possuem como para os migrantes rurais nas cidades, de primeira, segunda e terceiras gerações [...]. Um rural onde os agricultores vêm pondo em prática estratégias de diversificação de seus estabelecimentos, de pluriatividade, de associativismo, de agroindustrialização em pequena escala, enfim, estratégias de valorização das oportunidades que o espaço local e a região oferecem para viabilizar sua reprodução tanto como agricultores quanto como rurais. (FERREIRA, 2002, p. 39)

Se, por um lado, a economia brasileira voltava-se para o mercado externo, como fruto do processo de dependência e submissão de seu mercado ao exterior, por outro, o espaço rural passa a se configurar como espaço de luta por pertencimento à terra e reivindicação de autonomia produtiva para esses países.

A partir da década de 90, a literatura das ciências sociais especializadas passou a apontar reiteradamente as potencialidades do rural como espaços para reformas societárias de cunho integrativo e como base para se repensar a qualidade de vida na contemporaneidade. O fundamento dessa nova visão residia no fato de que, em diversos países, registravamse processos de recomposição dos espaços rurais (retomada do crescimento demográfico, diversificação ocupacional, aumento na oferta de trabalho etc). Mais do que isto: a nova visão refletia o fato de que se estavam organizando, em vários países, associações e movimentos sociais de base rural que propunham uma forte crítica às políticas rurais e agrícolas gestadas conforme o modelo de desenvolvimento 
modernizador; movimentos sociais que evidenciavam sua disposição para se tornarem atores coletivos da revitalização do rural (FERREIRA, 2002, p. 30)

Na visão de Ferreira (2002), esse processo, no Brasil, manifesta-se, principalmente, na atuação de movimentos sociais em reivindicação da reforma agrária:

No Brasil, a perspectiva de se pensar o rural como território do futuro é demonstrada de forma exemplar pela mobilização dos sem-terra e pelos assentamentos rurais que evidenciam sua potencialidade para uma política de combate à fome e à exclusão social. Há uma revitalização rural em curso, mesmo que desigual em diferentes territórios. Certas regiões passam por processos contínuos de exclusão e marginalização, ao passo que outros territórios rurais detêm chances de trabalho, de cultura e sociabilidades que são cada vez mais valorizadas. (FERREIRA, 2002, p. 41)

Leonilde Servolo de Medeiros (2001) analisou as experiências dos produtores do Sul que se aventuraram nas propostas do governo para a conquista do Norte e CentroOeste do país, na década de 1970. E que se organizaram para formar um movimento de luta em prol dos direitos dos pequenos produtores, sendo os principais atores de diversas manifestações ocorridas no início dos anos 1980 contra a política agrícola do governo.

Ocupando as ruas com suas máquinas, trancando as portas de bancos, procuravam denunciar os efeitos perversos da política de modernização e exigiam uma política agrícola que privilegiasse também os 'pequenos'. O segmento integrado à agroindústria (viticultores, fumicultores, suinocultores, avicultores, entre outros) constituiu novo adversário: não se tratava mais de ter como referência as políticas públicas, mas sim de questionar os termos dos contratos de integração. $O$ bloqueio dos portões das agroindústrias, a realização de 'greves', visando impedir a entrega dos produtos para processamento, foram algumas das iniciativas que marcaram a trajetória desses grupos sociais e produziram a reiteração de sua identificação como trabalhadores. (MEDEIROS, 2001, p. 107-108) 


\section{Progresso tecnológico na agricultura e colapso ambiental}

Em se tratando de problemáticas ambientais, para Castoriadis (1987), quando o ser humano lida com ações cujo impacto pode aparecer daqui a vinte e cinco mil anos, por exemplo, ele deixa de se preocupar com os possíveis resultados dessa ação e, ainda mais: acredita que agir despreocupadamente em relação aos riscos dessa ação é legítimo. "Embora nos tenha sido dado um tempo linear e um horizonte temporal infinito, nós agimos como se o único intervalo de tempo significativo fosse o de alguns anos à frente" (CASTORIADIS, 1987, p. 155-156).

Para Castoriadis (1987), no contexto da modernidade, corre-se o risco de que a resolução e interpretação de problemas ambientais e ecológicos permaneçam "desconhecidos até o momento em que a catástrofe surge como ameaça" (CASTORIADIS, 1987, p. 154). Nesse sentido, "a crise atual avança rumo a um ponto no qual ou seremos confrontados com uma catástrofe natural ou social, ou então, antes ou depois disso, os homens reagirão de uma maneira ou de outra e tentarão estabelecer novas formas de vida social que tenham um sentido para eles" (CASTORIADIS, 1987, p. 158). Os mitos - como limitar a noção de desenvolvimento à esfera econômica e a crença de que só se atinge a felicidade e autorrealização por meio do consumo - "mais que o dinheiro e as armas, constituem o mais formidável obstáculo no caminho de uma reconstrução da sociedade humana" (CASTORIADIS, 1987, p. 158).

No Brasil, a industrialização no campo deve-se ao fato de que, em sua história econômica e social, o país usou a agricultura para sustentar suas demandas industriais. Ela trouxe à tona os problemas sociais rurais e urbanos, nos níveis nacional (devido aos impactos das ações estatais e do mercado financeiro) e regional (consequência das diferenças entre culturas agrícolas tradicionais de cada região e da discrepância entre os estados brasileiros quanto a seus níveis de desenvolvimento econômico e industrial), retomando temas como a renda da terra, propriedade territorial, reforma agrária, preço dos alimentos e matérias-primas, crédito rural (MÜLLER, 1982). A política agrícola governamental dedicou-se a "explorar a agricultura para financiar o crescimento 
industrial" em vez de "fomentar a produção agrícola e o bem-estar rural" (RODRIGUES, 1978, p. 36).

Para Müller (1982), o avanço da industrialização do campo no Brasil "permitiu um enriquecimento relativo generalizado da agricultura industrializada e um empobrecimento da tradicional". Isso porque, os agricultores industrializados, ao incorporarem progresso técnico, expandiram a acumulação de capital e as "correspondentes relações sociais de produção" (associação a oligopólios) (MÜLLER, 1982, p. 67). Logo, "a grande maioria dos estabelecimentos teve o seu ingresso no clube dos produtores modernos bloqueado", na medida em que "a industrialização do agro mantém com a estrutura industrial do país: uma pequena parcela de produtores [que] é responsável por enormes quantidades de produtos e de valor" (MÜLLER, 1982, p. 67).

Para Angela Duarte Damasceno Ferreira (2002), a crise da agricultura moderna fez com que o "apelo em favor de uma agricultura verde, sustentável e de boas práticas agrícolas" ganhasse importância científica (FERREIRA, 2002, p. 33). Esse apelo "cresce em todos os países de capitalismo avançado, ao lado das novas concepções de áreas protegidas e parques" (FERREIRA, 2002, p. 33). O rural passou a ser reconhecido como "ponto de contato por excelência entre sociedade e natureza", tendo importância central nos embates sobre meio ambiente (FERREIRA, 2002, p. 33). Ferreira (2002) lembra Marc Mormont (1997) para defender a associação do rural à qualidade ambiental e a relação entre os espaços rurais e urbanos. Trata-se de reconhecer que "a maioria dos problemas ambientais (água, paisagem, saúde ligada à alimentação)" permite revelar as interdependências entre os espaços rurais e urbanos (FERREIRA, 2002, p. 33).

Para Ademir Cazella e Bernard Roux (1999), "um verdadeiro processo de transformação do modelo agrícola implantado no pós-guerra está em curso". Trata-se da conformação de uma "nova dinâmica da agricultura", impulsionada por um "movimento maior de questionamento dos modelos de desenvolvimento agrícola rural", relacionado: 1. às crises na área da alimentação, que teriam provocado o aumento nas "exigências dos consumidores quanto à qualidade dos alimentos" e a legitimação das "formas de agricultura que não seguem os preceitos produtivistas" e; 2. à "crise do modelo de desenvolvimento urbano", expressa pelo "desemprego e pela marginalização de uma 
parcela importante da população", que teriam provocado uma revalorização do "meio rural enquanto espaço de vida e de trabalho" (CAZELLA; ROUX, 1999, p. 66-67).

Mesmo diante do cenário de colapso ambiental vivenciado na atualidade (MEA, 2005a; 2005b), há autores que reforçam a importância da agricultura industrializada e seus benefícios, e desconfiam das agriculturas emergentes e alternativas, apontando-as como geradoras de empecilhos para a agricultura moderna brasileira. Para Buainain et al. (2013), não compensa manter o que eles chamam de um "posicionamento ambíguo sobre o tema", ao se referirem à proposição e defesa de novas agriculturas emergentes e alternativas. Para eles, essa postura compromete a "continuidade da efetividade potencial" da empresa agrícola, sem garantir que "um padrão tecnológico alternativo venha, de fato, a nascer algum dia" (BUAINAIN et al., 2013, p. 113). Para eles, a elaboração dessas agriculturas alternativas: 1. exigiria um grande esforço científico e tecnológico, inclusive a criação de uma nova "ontologia científica"; 2. seria algo a longo prazo que, quando viável, comprometeria "profundamente" trajetórias de sucesso da agricultura moderna (BUAINAIN et al., 2013, p. 113).

diante do crescimento explosivo da demanda alimentar mundial, seria quimérica, para não dizer absurda, a proposta de difundir tecnologias chamadas 'alternativas', de uso local e de baixa produtividade, sob o pretexto de proteção ao ambiente e ainda ecoando as críticas do passado, que não correspondem mais ao cotidiano da agricultura. (BUAINAIN et al., 2013, p. 112)

A noção de MFA pode ser fortemente encontrada nos sistemas tradicionais de uso da terra. As populações tradicionais apresentam um modelo de ocupação do território e uso dos recursos naturais com fraca articulação com o mercado, produção voltada principalmente para o autoconsumo, baseado em uso intensivo de mão de obra familiar, tecnologias de baixo impacto e geralmente pautado por uma lógica sustentável (ARRUDA, 1999).

A lógica da MFA que predomina nos sistemas tradicionais de uso da terra se contrapõe aos princípios capitalistas. Para Dejours (2013), por exemplo, no capitalismo o 
trabalho se torna fonte de sofrimento e o ser humano só alcança a sensação de prazer e satisfação enquanto consumidor. A mercadoria torna-se, assim, um fetiche. Adquire valor social e ganha vida própria: coisas tornam-se ideal de realização humana enquanto as pessoas tornam-se coisas. A MFA, na sua concepção, propõe uma retomada de valores e significados humanos.

Andrade et al. (2014) revelam a contribuição dos agricultores para a conservação da biodiversidade local e para o desenvolvimento de agriculturas sustentáveis. Isso se manifesta no sentido de que os agricultores permanecem no meio rural, ali vivem, constituindo laços de identificação sociocultural com o local. Isso está atrelado ao "desenvolvimento de políticas públicas de sustentabilidade, de conservação e programas de Educação Ambiental que incluam a percepção e o conhecimento dos agricultores nos territórios e contextos rurais, em um processo emancipatório de participação e empoderamento" (ANDRADE et al, 2014, p. 2).

Sobre as comunidades que perdem o conhecimento de técnicas tradicionais de produção: "[foi constatado] um conjunto de consequências negativas nas regiões do globo em que esse sistema desapareceu, entre elas: insegurança alimentar, aumento de conflitos, dificuldades de acesso à terra e perda de identidade cultural" (DOROW; STERN; ULLER-GÓMEZ, 2015, p. 5). O conhecimento sobre essas técnicas tradicionais de cultivo é importante para as comunidades rurais, porque não se trata apenas de técnicas de produção. Elas garantem qualidade de vida a esses grupos, permanência no campo, manutenção de biodiversidade, conservação cultural, ordenação do território.

Na região do Vale do Ribeira, estado de São Paulo, domínio da Mata Atlântica, Adams et. al. (2013) verificaram que, nos lugares onde a técnica tradicional da roça de toco desapareceu, houve: diminuição da agrobiodiversidade com uma redução de $52 \%$ das variedades vegetais; aumento do uso de agrotóxicos e fertilizantes sintéticos; redução da heterogeneidade da paisagem; maior dependência do mercado (comprometimento da renda) para aquisição de alimentos; redução da capacidade de retornar à roça (resiliência) em caso de necessidade. Nesse último caso, a resiliência é comprometida pela perda da agrobiodiversidade; perda do etnoconhecimento; e porque, ao voltar a fazer roça, as áreas florestadas já tinham superado a idade legal para uso (ADAMS et. al., 2013). 


\section{Considerações finais}

Na medida em que a agricultura é subordinada à indústria no âmbito capitalista, o ser humano e as relações sociais são reificadas no contexto da agricultura. A multifuncionalidade da agricultura (MFA), por outro lado, desponta como uma perspectiva da agricultura fundada em propor novos paradigmas produtivos, partindo do princípio de que a agricultura desempenha funções fundamentais na dinâmica do desenvolvimento rural, considerando fortemente a importância do tecido social e cultural e a preservação dos recursos naturais no meio agrícola e rural.

Acreditamos que a MFA, ao propor novas perspectivas em torno da agricultura e do espaço rural, seus usos e funções, configura-se numa possível e fértil alternativa para repensar as externalidades negativas decorrentes do processo de submissão da agricultura à indústria. Trata-se de reconhecer que os problemas sociais e ambientais enfrentados atualmente advêm desse processo. Acreditamos que é importante reconhecer que existem outros paradigmas de produção e desenvolvimento, mais sustentáveis e possíveis, que têm funcionado em comunidades tradicionais e rurais, como lembrado neste artigo.

\section{Referências}

ADAMS, Cristina; MUNARI, Lucia Chamlian Munari; VAN VLIET, Nathalie; MURRIETA, Rui Sergio Sereni; PIPERATA, Barbara Ann; FUTEMMA, Celia; PEDROSO JR., Nelson Novaes; TAQUEDA, Carolina Santos; CREVELARO, Mirella Abrahão; SPRESSOLA-PRADO, Vânia Luísa. Diversifying Communities Incomes and Losing Landscape Complexity in Quilombola Shifting Cultivation Communities on the Atlantic Rainforest (Brazil). Human Ecology, Columbus, v. 41, n. 1, p.119-137, 2013.

ANDRADE, Horasa Maria Lima da Silva; ANDRADE, Luciano Pires de; TELINO JR., Wallace Rodrigues; MUNIZ, Lauana Souza; NORONHA, Cartiele Rosale Borges de; LYRA-NEVES, Rachel Maria de. Conhecimento e interações dos agricultores do semiárido pernambucano em relação à avifauna local. In: Encontro da Rede de Estudos Rurais "Desigualdade, exclusão e conflitos nos espaços rurais", 6., 2014, Campinas SP, Brasil.

Anais Eletrônicos... Campinas: UNICAMP. 2014. 10p. Disponível em: https://docplayer.com.br/14158040-Gt-06-alternativas-agricolas-discursos-de-justificacaoe-de-contraposicao-ao-produtivismo.html. Acesso em: 24 out. 2020. 
ARRUDA, Rinaldo. " Populações tradicionais" e a proteção dos recursos naturais em unidades de conservação. Ambiente \& sociedade, Campinas, n. 5, p. 79-92, 1999.

BIELSCHOWSKY, Ricardo. Emerência do professor Antonio Barros de Castro. Revista de Economia Contemporânea, Rio de Janeiro, v. 15, n. 2, p. 362-369, 2011.

BUAINAIN, Antônio Márcio; ALVES, Eliseu; SILVEIRA; José Maria da; NAVARRO, Zender. Sete teses dobre o mundo rural brasileiro. Revista de política agrícola, Brasília, v. 22, n. 2, p. 105-121, 2013.

CARNEIRO, Maria José; MALUF, Renato Sérgio. Para além da produção:

multifuncionalidade e agricultura familiar. Rio de Janeiro: Mauad, 2003. 230p.

CASTORIADIS, Cornelius. Encruzilhadas do labirinto Il: os domínios do homem. São Paulo: Paz e Terra, 1987.

CASTRO, Antonio de Barros. Sete ensaios sobre a economia brasileira. São Paulo, Rio de Janeiro: Editora Forense, 1969. v. 1, 191 p.

CAZELLA, Ademir Antonio; ROUX, Bernard. Agribusiness em questão: a emergência da agricultura multifuncional. Estudos sociedade e agricultura, Rio de Janeiro, v. 13, n. 10, p. 46-69, 1999.

DEJOURS, Christophe. A sublimação, entre sofrimento e prazer no trabalho. Revista Portuguesa de Psicanálise, Lisboa, v. 33, n. 2, p. 9-28, 2013.

DOROW, Reney; STERN, Ivonete Lenir; ULLER-GÓMEZ, Cíntia. Da reinterpretação de sistemas tradicionais de uso da terra à construção social de mercados com os agricultores familiares da roça de toco de Biguaçu-SC. Novos Cadernos NAEA, Belém, v. 18, n. 1, 2015.

DUMONT, Louis. Homo aequalis. Paris: Gallimard, 1977.

DUMONT, Louis. Homo hierarchicus. Paris: Gallimard. 1966.

DUMONT, Louis. On the comparative understandins of non-modern civilizations. [S.n.]: Daedalus, 1975.

DUMONT, Louis. Religion, politics and society in the individualist universe. In: PROCEEDINGS OF THE ROYAL ANTHROPOLOGICAL INSTITUTE. Londres: [S.I], 1971. p. 3141.

ELIAS, Norbert. A sociedade dos indivíduos. Rio de Janeiro: Zahar, 1994. 
FERNANDES, Bernardo Mançano; WELCH, Clifford Andrew; GONÇALVES, Elienai Constantino. Debates sobre políticas fundiárias e usos da terra no Brasil. São Paulo: Cultura Acadêmica: UNESCO, 2014. 112p.

FERREIRA, Angela Duarte Damasceno. Processos e sentidos sociais do rural na contemporaneidade: indagações sobre algumas especificidades brasileiras. Estudos sociedade e agricultura, Rio de Janeiro: CPDA: UFRRJ, n.18, p. 28-46, 2002.

FIORI, José Luís. Para repensar o papel do Estado sem ser um neoliberal. Revista de Economia Política, São Paulo, v. 12, n. 1, p. 76-90, jan./mar. 1992.

FRANCO ALVES, Arilde; MALAGODI, Edgard Afoinso. Multifuncionalidade da Agricultura: retórica ou ferramenta de análise do Desenvolvimento Rural? REVISTA ALASRU Análisis Latinoamericano del Medio Rural, Nueva Época, n. 9, p. 117-137, 2014.

FRANK, Andre Gunder. Capitalism and underdevelopment in Latin America: Historical Studies of Chile and Brazil. New York: Monthly Review Press, 1967.

GUDYNAS, Eduardo. Locomotoras, bolsas, pies y senderos: imagenes del extractivismo. Revista Quehacer, Lima, n. 187, p. 106-118, jul./set. 2012.

GUDYNAS, Eduardo. Locomotoras, bolsas, pies y senderos: imagenes del extractivismo. Revista Quehacer, n. 187, p. 106-118, 2012.

INTA. Análisis de la cadena de la soja en la Argentina. Estudios Socioeconómicos de los Sistemas Agroalimentarios y Agroindustriales Nª 3. Buenos Aíres: Ediciones de INTA. 2009.

KURZ, Robert. O colapso da modernização: da derrocada do socialismo de caserna à crise da economia mundial. Rio de Janeiro: Paz e Terra, 1999.

LE GOFF, Jacques et al. Memória e história. Enciclopédia Einaudi. Tomo I. Lisboa: Imprensa Nacional - Casa da Moeda, 1984. v. 1, p. 260-293.

LEITE, Sérgio Pereira. Estado, padrão de desenvolvimento e agricultura: o caso brasileiro. Estudos Sociedade e Agricultura, Rio de Janeiro, v. 13, n. 2, p. 280-332, 2005.

MANDEL, Ernest. A Formação do Pensamento Econômico de Karl Marx. Rio de Janeiro: Zahar, 1968. 211p.

MARQUES, Paulo Eduardo Moruzzi; DE GASPARI, Luciane; ALMEIDA, Bruna. Organização de Controle Social (OCS) e engajamento agroecológico das famílias do assentamento Milton Santos no estado de São Paulo. Estudos Sociedade e Agricultura, p. 545-560, 2017. 
MARTINS, Luciano. A crise do nacional-desenvolvimentismo. Folha de S. Paulo, São Paulo, p. 1-3, 29 dez. 1991.

MEA. Millennium Ecosystem Assessment. Ecosystem and human well-being: biodiversity synthesis. In: WORLD RESOURCES INSTITUTE. Washington: [S.I.] 2005a. 86p.

MEA. Millennium Ecosystem Assessment. Ecosystems and human well-being: synthesis. Washington: Island Press, 2005b. 137p.

MEDEIROS, Leonilde Servolo de. Sem Terra, “Assentados”, “Agricultores familiares”: considerações sobre os conflitos sociais e as formas de organização dos trabalhadores rurais brasileiros. In.: GIARRACCA, Norma. (Comp.) |Una nueva ruralidad en América Latina? Buenos Aires: CLACSO, p. 103-128, 2001.

MELLOR, Jobn W. O planejamento do desenvolvimento agrícola. Rio de Janeiro: O Cruzeiro, 1967.

MORMONT, Marc. A la recherche des spécificités rurales. In: JOLLIVET, Marcel. (org.) Vers un rural postindustriel; rural et environnement dans huit pays européens. Paris:

L'Harmattan, 1997.

MORUZZI MARQUES, Paulo Eduardo; DE LUCAS, Ademir; TRIVELLATO, Gabriela Maria Leme. O Papel da Extensão Universitária no apoio à Agricultura Familiar no município de São Pedro/SP. Rev. Cult. Ext. USP, São Paulo, v. 18, p. 13-23 nov, 2017.

MORUZZI MARQUES, Paulo Eduardo de; LACERDA, Tatiana Ferreira Nobre de. Agricultura orgânica, representação territorial e reprodução social da agricultura familiar: os agricultores ecologistas da serra geral em Santa Catarina. Ruris, Campinas, v. 2, n. 2, p. 137-158, set. 2008.

MÜLLER, Geraldo. Agricultura e industrialização do campo no Brasil. Revista de economia política, São Paulo, v. 2, n. 6, p. 47-77, 1982.

PETRAS, James. El capitalismo extractivo y las diferencias em el bando latino-americano progresista. Rebelión, Madrid, 8 maio 2012. Disponível em:

http://www.rebelion.org/noticia.php?id=149207. Acesso em: 19 dez. 2019.

PORTELLA FILHO, Petrônio. Ajustamento na América Latina: crítica ao modelo de Washington. Ensaios FEE, Porto Alegre, v. 15, n. 1, p. 205-233, 1994.

RODRIGUES, José de Arimatéia. O papel da agricultura no processo de desenvolvimento econômico e as políticas governamentais para o setor agrícola. Revista de Administração Pública, Rio de Janeiro, v. 12, n. 3, p. 9-37, 1978. 
ROUX, Bernard; FOURNEL, Estelle. Multifuncionalidade e emprego nos estabelecimentos rurais franceses: um estudo nas zonas montanhosas de LanguedocRoussillon. In: CARNEIRO, Maria José; MALUF, Renato Sérgio. Para além da produção: multifuncionalidade e agricultura familiar. Rio de Janeiro: Mauad, 2003. p. 169-199.

TORUNSKY, Flavia. Justificativas em torno das Comunidades que Sustentam a Agricultura: um estudo de caso da CSA São Carlos/SP. Dissertação (Mestrado em Ecologia Aplicada) - Escola Superior de Agricultura “Luiz de Queiroz”, Centro de Energia Nuclear na Agricultura. Piracicaba, 2019, 2137p.

TRIVELLATO, Gabriela Maria Leme; DOS SANTOS, Mayara Araújo. O Papel dos Seres Humanos na Manutenção dos Ecossistemas. Revista Relicário, v. 6, n. 11, p. 104-116, 2019.

VÁSQUEZ CARDONA, David. La agroecología confrontando al agronegocio. Bases para latransformación de las relaciones sociales de producciónenel campo. REVISTA ALASRU Análisis Latinoamericano del Medio Rural, Nueva Época, n. 9, p. 139-163, 2014. 